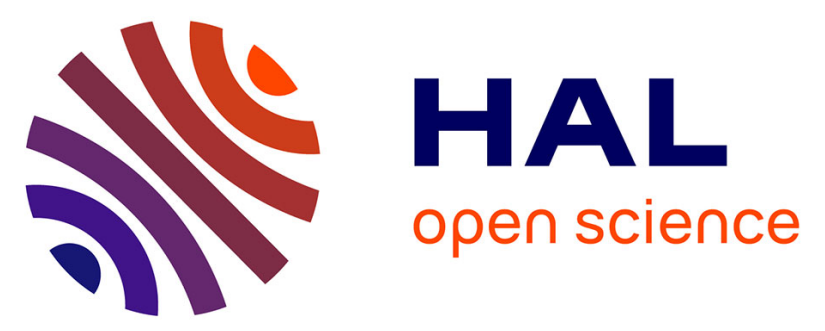

\title{
Transport of metals and sulphur in magmas by flotation of sulphide melt on vapour bubbles
}

James.E. Mungall, James M. Brenan, B Godel, S.J. Barnes, Fabrice Gaillard

\section{To cite this version:}

James.E. Mungall, James M. Brenan, B Godel, S.J. Barnes, Fabrice Gaillard. Transport of metals and sulphur in magmas by flotation of sulphide melt on vapour bubbles. Nature Geoscience, 2015, 8, pp.216-219. 10.1038/ngeo2373 . hal-01128839

\section{HAL Id: hal-01128839 \\ https://hal.science/hal-01128839}

Submitted on 10 Mar 2015

HAL is a multi-disciplinary open access archive for the deposit and dissemination of scientific research documents, whether they are published or not. The documents may come from teaching and research institutions in France or abroad, or from public or private research centers.
L'archive ouverte pluridisciplinaire HAL, est destinée au dépôt et à la diffusion de documents scientifiques de niveau recherche, publiés ou non, émanant des établissements d'enseignement et de recherche français ou étrangers, des laboratoires publics ou privés. 
Transport of metals and sulphur in magmas by flotation of sulphide melt on vapour bubbles J. E. Mungall ${ }^{1}$, J. M. Brenan ${ }^{1}$, B. Godel ${ }^{2}$, S. J. Barnes ${ }^{2}$, F. Gaillard ${ }^{3}$

${ }^{1}$ Department of Earth Sciences, University of Toronto, 22 Russell St, Toronto, ON, M5S 3B1, Canada

${ }^{2}$ CSIRO Mineral Resources Flagship, 26 Dick Perry Ave, Kensington, WA, 6151, Australia

${ }^{3}$ CNRS-Université d'Orléans-BRGM, UMR 7327, 1A, rue de la Férollerie, 41071 Orléans, France

Emissions of sulphur ${ }^{1,2}$ and transition metals ${ }^{3,4}$ from magmas in the shallow crust have global impacts on human society by affecting climate after volcanic eruptions ${ }^{5,6}$ and by forming giant copper and gold ore deposits, which are massive anomalies of sulphur as well as of the ore metals themselves ${ }^{3,4,7,8}$. These emissions vastly exceed the amounts that could have been derived from the associated magmas themselves ${ }^{2}$. Intrusion of denser, hotter, vapourand sulphide-saturated magma beneath the cooler and more buoyant bodies that are finally erupted is the most probable source of the excess sulphur and metals in eruptive or hydrothermal systems ${ }^{1,4,9,10}$. However, the mechanism for the selective upward transfer of sulphur and metals remains poorly understood, because their main carrier phase, sulphide melt, is dense and is generally assumed to settle to the bottoms of magma bodies. Here we show, by experimental observation and by gas speciation and mass balance models, that such transfers may be achieved by the flotation of compound drops ${ }^{11}$ comprising droplets of sulphide melt attached to vapour bubbles. By proposing and demonstrating the feasibility of a novel physical mechanism for upward mobility of sulphide liquids, our work provides a mechanism for massive atmospheric releases of sulphur and contradicts widely held assumptions that dense sulphide liquids rich in sulphur, copper, and gold will remain sequestered in the crust. 
Plinian volcanic eruptions typically release as much as 100 times more sulphur than could have been dissolved within the erupted volumes of felsic magma ${ }^{2,12,13}$. Sulphur is emitted during quiescent periods between eruptions at rates far exceeding plausible rates of supply from the felsic magmas within the shallow volcanic feeders ${ }^{2,10}$. Excess sulphur emissions result from eruptive tapping of apical gas-rich cupolas containing excess vapour which comprises up to 30 vol\% of the magma in shallow intrusions ${ }^{1,14}$.

Intrusion of sulphur-rich mafic magma immediately prior to eruption, commonly saturated with droplets of an immiscible Fe-(Cu)-(Ni)-S-O liquid (i.e., sulphide liquid) ${ }^{15,16}$, may trigger eruptions of felsic to intermediate magma, while the bulk of the mafic magma remains at depth ${ }^{17}$. However the co-erupted excess sulphur vapour at Soufriere and Pinatubo volcanoes was probably supplied previously by degassing of underplated mafic magma over protracted periods $^{1,2,10,18}$.

Transition metals are also transferred from mafic magmas saturated with sulphide liquid into overlying felsic liquids, leading to enrichment of ore-forming elements. Hydrothermal porphyry deposits of $\mathrm{Cu}$ and or $\mathrm{Au}$ at Pinatubo as well as Bingham Canyon, Utah ${ }^{19}$ and Bajo de la Alumbrera, Argentina ${ }^{3,8}$, form when those felsic magmas solidify and discharge metal- and sulphur-rich aqueous fluids. Although intimate interactions between mafic and felsic magmas undoubtedly occur, the physical mechanism by which sulphur and metals are transferred between them remains a matter of speculation.

Orthomagmatic ore-forming fluids have ratios of transition metals similar to those of the sulphide liquid from which they were derived by hydration or oxidation during quantitative 
resorption of sulphide liquid by silicate magma; e.g., $\mathrm{Cu} / \mathrm{Au}$ at the Bajo de la Alumbrera porphyry $\mathrm{Cu}-\mathrm{Au}$ deposit ${ }^{3}$ and $\mathrm{Cu} / \mathrm{Ni}$ and $\mathrm{Cu} / \mathrm{Co}$ in volcanic gases at Merapi ${ }^{4}$. At the Bajo de la Alumbrera mafic magma mixed with rhyodacite magma to produce hybrid andesites with mixed phenocryst populations containing sulphide melt inclusions ${ }^{3}$. Groundmass sulphide is not observed in any rock types, presumably due to subsequent hydration of sulphide and degassing, e.g.,

$\mathrm{H}_{2} \mathrm{O}_{\text {(silicate melt) }}+\mathrm{FeS}_{\text {(sulphide melt) }}=\mathrm{FeO}_{\text {(silicate melt) }}+\mathrm{H}_{2} \mathrm{~S}_{\text {(vapour) }} \quad 1$,

$3 \mathrm{H}_{2} \mathrm{O}_{\text {(silicate melt) }}+\mathrm{FeS}_{\text {(sulphide melt) }}=\mathrm{FeO}_{\text {(silicate melt) }}+\mathrm{SO}_{2 \text { (vapour) }}+3 \mathrm{H}_{2 \text { (vapour) }}$

These reactions are favored at low pressure and high $\mathrm{H}_{2} \mathrm{O}$ activity in FeO-poor felsic magmas, especially if vapour is able to leave the system. The mineralized dacite porphyry stocks at Alumbrera were derived from the top of a stratified intrusion, where sulphide melt was not stable, whereas the sulphide melt was present in the more mafic hybrid andesitic melt at the bottom $^{3}$; the authors suggest that fluids must have extracted metals and sulphur from the entire stratified magma body despite the shallow intrusions having tapped only the top, while preserving the $\mathrm{Cu} / \mathrm{Au}$ ratios of the sulphide liquids found only at the base of the system ${ }^{3}$.

Solidified remnants of sulphide liquid globules that have undergone breakdown to Cu-sulphide phases and Fe-oxide minerals occur in quenched felsic to intermediate magmas at Pinatubo, Bingham Canyon, Merapi, Popocatepetl, Satsumi-Iwojima, Clear Lake, and Mount St Helens ${ }^{4,16,19,20}$. These examples of sulphide melt which was clearly not at equilibrium with its host magma, have previously been accounted for either as hybrids of sulphide-saturated mafic liquids with initially sulphur-poor felsic magmas, or as the result of vapour transport of sulphur 
and metals out of mafic magma into felsic magma followed by their reprecipitation in sulphide liquid droplets which subsequently became unstable ${ }^{15}$.

A more parsimonious explanation for addition of sulphur, $\mathrm{Cu}$, and $\mathrm{Au}$ to either shallow preeruptive or ore-forming intrusions would have the sulphide melt being physically elevated toward the top of the stratified magma body where it then underwent congruent dissolution via hydration during volatile exsolution. However this possibility has not been entertained previously because of the well-documented density contrast between sulphide melt and silicate melt, which promotes settling of sulphide liquid toward to the base of a magmatic system.

We have performed experiments in which sulphide melt, silicate melt, and vapour were equilibrated to measure the interface morphologies ${ }^{21-23}$. Sulphide drops preferentially occur at the interface between silicate melt and vapour (Fig. 1a), despite the gravitational body force that tends to pull the sulphide melt to the base of the experimental charge. Topologically identical relationships were observed in evacuated silica tubes with a low-density atmosphere governed by equilibrium with sulphide melt ${ }^{23}$, in a gas-mixing furnace under an inert $\mathrm{Ar}$ atmosphere $^{21}$, and at $200 \mathrm{MPa}$ under water-saturated conditions with 3.2 wt\% $\mathrm{H}_{2} \mathrm{O}$ dissolved in the silicate melt ${ }^{22}$, indicating that the surface energies of the interfaces are not dramatically affected by the composition of the vapour phase. Under high acceleration in a centrifuge the sulphide descends to the base of the charge, not in contact with the vapour phase ${ }^{23}$. However, during quench of the centrifuge experiments and consequent degassing of the sulphide droplets, smaller droplets of sulphide melt rise from the main droplet at the base of the charge, pendant from ascending vapour bubbles (Extended Data Figure 2). Where silicate melt, sulphide melt, and vapour have been co-entrapped in minerals ${ }^{4,24,25}$; sulphide melt always 
occurs attached to the vapour bubble. Sulphide melt droplets attached to vapour bubbles have been noted in komatiitic Ni sulphide ores ${ }^{26}$.

We have used high resolution computed X-ray tomography ${ }^{27}$ to measure precisely the shapes of interfaces separating sulphide, silicate, and vapour in quenched run products of two experiments (Fig. 1). Comparison of quenched sulphide drops with their shapes as observed in situ at experimental conditions using conventional medical X-radiography ${ }^{21}$ allows us to estimate qualitatively the interfacial tensions of all three types of interface; sulphide-silicate, sulphide-vapour, and silicate-vapour (Table S1, Extended Data; Supplementary Information). The shapes of interfaces between sulphide melt and silicate melt are unaffected during quench, permitting quantitative solution of the Bashforth-Adams equation to determine interfacial tensions on quenched experimental run products identical to values determined on Xradiographs of sessile drops imaged in situ at run conditions (Supplementary Information). The shapes of pendant sulphide drops both in situ and in quenched experimental products are such that for small droplets where surface energy dominates over buoyant body forces the total energy of a system containing all three phases is always at a minimum when the sulphide occurs at the interface between silicate melt and vapour, forming a compound drop ${ }^{11}$. We infer that in any magmatic system undergoing vapour nucleation and bubble growth where sulphide melt is also a stable phase, the sulphide droplets will spontaneously occur attached to vapour bubbles.

We propose that the requirement for sulphur and metals to be transferred from mafic magmas to overlying felsic magmas, whilst preserving metal ratios characteristic of the sulphide melts themselves, is most easily met by upward transport of sulphide as compound drops, lofted by 
the relatively high buoyancy of the attached vapour bubbles (Figs. 2,3). We have modeled the evolution of vapour bubbles in an idealized closed system undergoing isothermal decompression ${ }^{28}$ (Supplementary Information). We compare the evolution of an andesitic magma initially comprising $0.1 \mathrm{wt} \%$ of vapour at 2600 bars, $1050{ }^{\circ} \mathrm{C}$, with that of an initially identical magma also containing compound droplets of sulphide and vapour wherein sulphide comprises $3.3 \mathrm{wt} \%$ of the entire system, to simulate the evolution of a single sulphide droplet as a vapour bubble nucleates next to it and then grows during decompression. At all pressures the vapour phase is buoyant with respect to the silicate magma; with the growth of the attached bubble the density of the compound drop falls until it becomes buoyant at pressures less than 2000 bars. By the time the compound drop has risen to pressures less than 1,000 bar, the sulphide drop comprises only $1 / 25$ th of the volume of the compound drop, a value that falls to infinitesimal proportions at the lowest pressures. Such small quantities of sulphide liquid adhering to bubbles would be difficult to observe. The gas evolves from $\mathrm{CO}_{2}$-rich with sulphur species dominated by $\mathrm{H}_{2} \mathrm{~S}$ to being nearly pure $\mathrm{H}_{2} \mathrm{O}$ at low pressure (Fig. 2, inset). At the very lowest pressures $\mathrm{SO}_{2}$ rises to comprise nearly half of the sulphur budget of the vapour in the case of the compound drop whereas under sulphide-absent conditions the sulphur speciation becomes strongly $\mathrm{SO}_{2}$-dominated at very low pressure (Extended Data Fig. 9). The total mass of sulphur residing in the vapour phase at pressures below 5 bar is $1.3 \%$ of the mass of the magma, more than 20 times higher in the case of the compound drop than in the case of the isolated bubble. Sulphur loads of this magnitude are sufficient to explain the excess sulphur paradox alluded to in the introductory paragraph. 
It is quite clear that compound drops, rather than isolated fluids, are necessary to explain the $\mathrm{Cu}$ and $\mathrm{Au}$ concentrations of the ore-forming fluids at Alumbrera ${ }^{3,29}$ (Fig. 3). Model compound drop compositions coincide with the bulk ore ${ }^{29}$, average ore-forming brines ${ }^{29}$ and many of the sulphide melt inclusions from Alumbrera ${ }^{3}$, all close to $\mathrm{Cu} / \mathrm{Au}=10^{4}$. Model supercritical vapours at equilibrium with sulphide liquids follow a trend of increasing metal contents with decreasing pressure just below $\mathrm{Cu} / \mathrm{Au}=10^{3}$, whereas model supercritical vapours not equilibrated with sulphide liquids have Au contents that fall as pressure decreases but nearly constant $\mathrm{Cu}$ contents. Also shown are two trends of coexisting brine and vapour that would form if the modeled supercritical vapours were to fall within the miscibility gap separating hydrosaline melts (i.e., brines) from low-density aqueous vapours if the system contained sufficient $\mathrm{Cl}$. Subcritical magmatic fluids are not expected to fractionate $\mathrm{Cu}$ from $\mathrm{Au}$.

Within a depressurizing compound drop, the amount of sulphide melt falls as the amount of vapour increases, drawing sulphur into the vapour phase. The metal budget of the compound drop as a whole changes very little because metal is transferred almost quantitatively from the sulphide melt to the vapour. We propose that the ore-forming magmatic volatile phase at Alumbrera shown in Figure 3 was composed of compound drops that completely consumed their attached load of sulphide. The removal of compound drops from deep in the magma plumbing system to shallow levels will effect the same net transfer of metals and sulphur into the shallow hydrothermal system regardless of whether it occurs as modeled here, at equilibrium with the host silicate magma (as would be expected in slowly rising crystal-rich magma), or if it occurs suddenly by rapid flotation of the compound drop from considerable depth (as might occur in hybrid intermediate magma at depth with low crystal content). Both 
sulphur and metals, formerly contained in sulphide melt at depth, are quantitatively transferred to the vapour phase by the time they reach low pressures.

The key to the process of sulphur and metal transfer to shallow or erupted fluid phases is the buoyancy of the compound drop. If the dense sulphide liquid did not form compound drops, the excess sulphur and metals would remain sequestered deep in the crust.

Our observations of compound sulphide liquid-vapour bubble drop formation demonstrate that whenever magma saturated with sulphide melt undergoes vesiculation and degassing, some or all of the sulphide melt should accompany the vapour phase upward instead of settling to the base of the mafic magma as is generally supposed, constituting a dramatically enhanced vector for upward transfer of sulphur and transition metals to ore-forming systems or to the atmosphere. The implications extend to the transport and deposition of $\mathrm{Ni}_{-}^{-}, \mathrm{Cu}-$, and Pt-rich sulphides in magmatic ore deposits, where it is clearly not safe to assume that sulphide melt will always tend to migrate downwards into structural traps. Flotation of sulphide drops and their ultimate release to $\mathrm{H}_{2} \mathrm{~S}$-rich vapours may also provide a mechanism to support the recent proposition that catastrophic end-Permian global climate change resulted from massive transfers of $\mathrm{Ni}$ to the atmosphere from mafic magmas ${ }^{30}$. It is intriguing to note that flotation of sulphide minerals on vapor bubbles is also the principal means used in the beneficiation of the ores that form in these magmatic and hydrothermal systems.

\section{Figures:}

Figure 1a: 3D tomographic image of heavy compound drop comprising a small vapour bubble and large sulphide drop and a second sulphide drop pendant from the meniscus, which would 
float if the vapour was detached from the enclosing chromite crucible, quenched after being held at $1200^{\circ} \mathrm{C}$ for 48 hours. Yellow - Fe-Ni-Cu-S-O liquid; blue - vapour; colourless - basaltic silicate melt. The diameter of the contact line joining the pendant drop to the meniscus is 0.4 $\mathrm{mm}$. Inset: 2D slice through the X-ray tomographic image of the same experiment, showing the lower compound drop attached to the base of the chromite crucible (light grey) and a smaller compound drop at the lower right.

Figure 1b: Morphologies of compound drops for various ratios of surface tensions between sulphide melt, silicate melt, and vapour ${ }^{11}$. In all of the cases shown the volume of the vapour bubble is the same, and it is three times that of the sulphide drop. For combinations of surface tensions falling outside the bold black lines, there is no three-phase contact line because two of the three phases are repelled by one another and do not make contact. Observed experimental and natural sulphide-vapour compound drops fall to the far left hand side of the diagram.

Figure 2: cross sectional cartoon illustrating sulphide flotation in subvolcanic environments. Buoyant compound drops formed in the zone of hybridization of sulphide-saturated mafic magma and felsic magma rise into felsic magma where they are destroyed by hydration at low pressure, releasing $\mathrm{H}_{2} \mathrm{~S}$ and metals to a vapour phase which may be erupted or may form hydrothermal mineral deposits. Inset panel: $\Sigma \mathrm{S}$ and $\mathrm{XH}_{2} \mathrm{O}$ are total mole fractions of sulphur species and water vapour respectively, $\mathrm{SO}_{2} / \Sigma \mathrm{S}$ shows speciation of oxidized over total $\mathrm{S}, \mathrm{V}_{\mathrm{S}} / \mathrm{V}_{\mathrm{v}}$ is volume of sulphide/volume of vapor in the compound drop, $\rho_{\mathrm{CD}}$ is bulk density of the compound drop during decompression of a compound drop. The evolution of vapour with the 
same initial composition but not subsequently re-equilibrated with sulphide melt is shown in the Extended Data, Figure 9.

Figure 3: Cu vs Au for modeled and measured compositions of sulphides, fluids, and ores at Alumbrera ${ }^{3,29}$. Model trends run from square terminations at 2600 bar to arrow terminations at 2.7 bar. SCF - supercritical fluid; SCF,SS - supercritical fluid at equilibrium with sulphide melt; trends of vapour-brine pairs at 2600 bar and at 2.7 bar run from 90:10 vapour:brine at square terminations to 10:90 vapour:brine at arrow terminations. The model methods are described in the Supplementary Information. Compound drops (heavy grey arrow) have nearly constant bulk compositions coincident with both ore-forming brines and with average ore at Alumbrera, whereas fluids alone do not ever have compositions similar to ore, even if they separate into metal-rich brines and metal-poor vapours.

\section{Methods Summary}

Backscattered electron (BSE) images of axial cross sections of experimental charges or published images of charges from previous studies ${ }^{21-23}$ were used to estimate the radii and contact angles of interfaces between quenched sulphide liquid, silicate glass, and vapour. Readers are referred to those previous publications for further details of experimental methods. Because the experiments were all performed in cylindrical capsules, it was assumed that all three types of interface are spherical caps for small drops.

Two experiment run products were scanned at the Australian Resources Research Centre in Perth (Western Australia) using an XRADIA (now Zeiss) XRM 500 high-resolution threedimensional X-ray microscope system. The scanner was set up a voltage of $160 \mathrm{kV}$, a power of 
$10 \mathrm{~W}$, a voxel size of 1.16 micrometers and used built in dynamic ring removal artefacts allowing to image the interior of the capsule and to reduce potential artefacts. A total of 2000 projections were used to reconstruct a three-dimensional volume of the sample. The resulting dataset was processed using dedicated image processing procedures using AvizoFire(r) software combined with dedicated CSIRO-developed workflows ${ }^{27}$ to separate sulphide droplets from silicate and vapour phases and generate 3-D isosurfaces. Cartesian coordinates of numerous points on each interface were determined using Corel Photopaint ${ }^{\mathrm{TM}}$ and used to fit model spherical caps by least squares error minimization for small drops, or compared with the Adams-Bashforth equation for larger sessile drops as described in the Supplementary Information.

\section{References}

1 Wallace, P.J. Volcanic SO2 emissions and the abundance and distribution of exsolved gas in magma bodies. J. Volc. Geoth. Res. 108, 85-106 (2001).

2 Wallace, P.J. \& Edmonds, M. The sulfur budget in magmas: Evidence from melt inclusions, submarine glasses, and volcanic gas emissions. Rev. Mineral. Geochem. 73, 215-246 (2011).

3 Halter, W.E., Heinrich, C.A. \& Pettke, T. Magma evolution and the formation of porphyry CuAu ore fluids: evidence from silicate and sulfide melt inclusions. Mineral. Dep. 39, 845-863 (2005). 
4 Nadeau, O., Williams-Jones, A.E. \& Stix, J. Sulphide magma as a source of metals in arc-related magmatic hydrothermal ore fluids. Nature Geosci. 3, 501-505 (2010).

5 Devine, J.D., Sigurdsson, H., Davis, A.N. \& Self, S. Estimates of sulfur and chlorine yield to the atmosphere from volcanic eruptions and potential climatic effects. J. Geophys. Res. 89 B7, 6309-6325 (1984).

6 Santer, B.D. et al. Volcanic contribution to decadal changes in tropospheric temperature. Nature Geosci. 7, 185-189 (2014).

7 Hunt, J.P. Pophyry copper deposits. Econ. Geol. Monogr. 8, 192-206 (1991).

8 Halter, W.E., Pettke, T. \& Heinrich, C. The origin of Cu/Au ratios in porphyry-type ore deposits. Science 296, 1844-1846 (2002).

9 Edmonds, M. New geochemical insights into volcanic degassing. Phil. Trans. Math. Phys. Eng. Sci. 366, 4559-4579 (2008).

10 Edmonds, M. et al. Excess volatiles supplied by mingling of mafic magma at an andesite arc volcano. Geochem. Geophys. Geosys. Q04005, doi:10.1029/2009GC002781 (2010).

11 Neeson, M.J., Tabor, R.F., Grieser, F., Dagastine, R.R. \& Chan, D.Y.C. Compound sessile drops. Soft Matter 8, 11042-11050 (2012).

12 Westrich, H.R. \& Gerlach, T.M. Magmatic gas source for the stratospheric SO2 cloud from the June 15, 1991, eruption of Mount Pinatubo. Geology 20, 867-870 (1992). 
13 Gerlach, T.M., Westrich, H.R., Casadevall, T.J. \& Finnegan, D.L. Vapour saturation and accumulation in magmas of the 1989-1990 eruption of Redoubt Volcano, Alaska. J. Volcan. Geoth. Res. 62, 317-337 (1994).

14 Keppler, $\mathrm{H}$. The distribution of sulfur between haplogranitic melts and aqueous fluids. Geochim. Cosmochim. Acta 74, 645-660 (2010).

15 Hattori, K. High-sulfur magma, a product of fluid discharge from underlying mafic magma: evidence from Mount Pinatubo, Philippines. Geology 21, 1083-1086 (1996).

16 Di Muro, A. et al. Pre-1991 sulfur transfer between mafic injections and dacite magma in the Mt. Pinatubo reservoir. J. Volcan. Geoth. Res. 175, 517-540 (2008).

17 Pallister, J.S., Hoblitt, R.P., Meeker, G.P., Knight, R.J. \& Siems, D.F. Magma mixing at Mount Pinatubo: petrographic and chemical evidence from the 1991 deposits. In Newhall, C.G., Punongbayan, R.S. (Eds.), Fire and Mud: Eruptions and Lahars of Mount Pinatubo, Philippines. Univ. Wash. Press, Seattle, WA, pp. 687-731 (2004).

18 Van Hoose, A.E., Streck, M.J., Pallister, J.S. \& Wälle, M. Sulfur evolution of the 1991 Pinatubo magmas based on apatite. J. Volcan. Geoth. Res. 257, 72-89 (2013).

19 Hattori, K. \& Keith, J.D. Contribution of mafic melt to porphyry copper mineralization: evidence from Mount Pinatubo, Philippines, and Bingham Canyon, Utah, USA. Mineral. Dep. 36, 799-806 (2001). 
20 Larocque, A.C.L., Stimac, J.A., Keith, J.D. \& Huminicki, M.A.E. Evidence for open-system behavior in immiscible Fe-S-O liquids in silicate magmas: implications for contributions of metals and sulfur to ore-forming fluids. Can. Mineral. 38, 1233-1249 (2000).

21 Mungall, J.E. \& Su, S. Interfacial tension between magmatic sulfide and silicate liquids: constraints on kinetics of sulfide liquation and sulfide migration through silicate rocks. Earth Planet. Sci. Lett. 234, 135-149 (2005).

22 Botcharnikov, R.E. et al. Behavior of gold in a magma at sulfide-sulfate transition: revisited. Amer. Mineral. 98, 1459-1464 (2013).

23 Mungall, J.E. \& Brenan, J.M. Partitioning of platinum-group elements and Au between sulfide liquid and basalt and the origins of mantle-crust fractionation of the chalcophile elements. Geochim. Cosmochim. Acta 125, 265-289 (2014).

24 Metrich, N., Schiano, P., Clocchiatti, R. \& Maury, R.C. Transfer of sulfur in subduction settings: an example from Batan Island (Luzon volcanic arc, Philippines). Earth Planet. Sci. Lett. 167, 1-14 (1999).

25 Timina, T.Yu., Sharygin, V.V. \& Golovin, A.V. Melt evolution during the crystallization of basanites of the Tergesh Pipe, Northern Minusinsk Depression. Geochem. Int. 44, 752-770 (2006).

26 Dowling, S.E., Barnes, S.J., Hill, R.E.T., Hicks, J.D., Komatiites and nickel sulfide ores of the Black Swan area, Yilgarn Craton, Western Australia. 2: Geology and genesis of the orebodies. Mineral. Dep. 39, 707-728 (2004). 
27 Godel, B. High-resolution X-ray computed tomography and its application to ore deposits:

From data acquisition to quantitative three-dimensional measurements with case studies from Ni-Cu-PGE deposits. Econ. Geol. 108, 2005-2019 (2013).

28 Gaillard, F., Scaillet, B., Arndt, N.T. Atmospheric oxidation caused by a change in volcanic degassing pressure. Nature 478, 229-232 (2011)

29 Ulrich, T., Günther, D., Heinrich, C.A. Gold concentrations of magmatic brines and the metal budgets of porphyry copper deposits. Nature 399, 676-679 (1999)

30 Rothman, D.H. et al. Methanogenic burst in the end-Permian carbon cycle. PNAS 111, 54625467 (2014).

Supplementary Information available online

Correspondance and requests for materials should be addressed to JEM.

Acknowledgements. JEM and JMB were supported by Discovery Grants from the Natural Sciences and Engineering Research Council of Canada; BG and SJB were funded by the CSIRO Mineral Resources Research Flagship, FG was supported by the European Research Council (ERC project \#279790).

Author Contributions: JMB did experiments; JEM did modeling of interfaces and metal mass balance and wrote the manuscript; BG did CT scanning and related data reduction; FG did gas speciation modeling, SJB, JMB and JEM contributed to the original concept. All authors discussed the results and edited the manuscript. 
Author information: Reprints and permissions information is available at www.nature.com/reprints. The authors declare no competing financial interests. Correspondence and requests for materials should be addressed to JEM (mungall@es.utoronto.ca). 


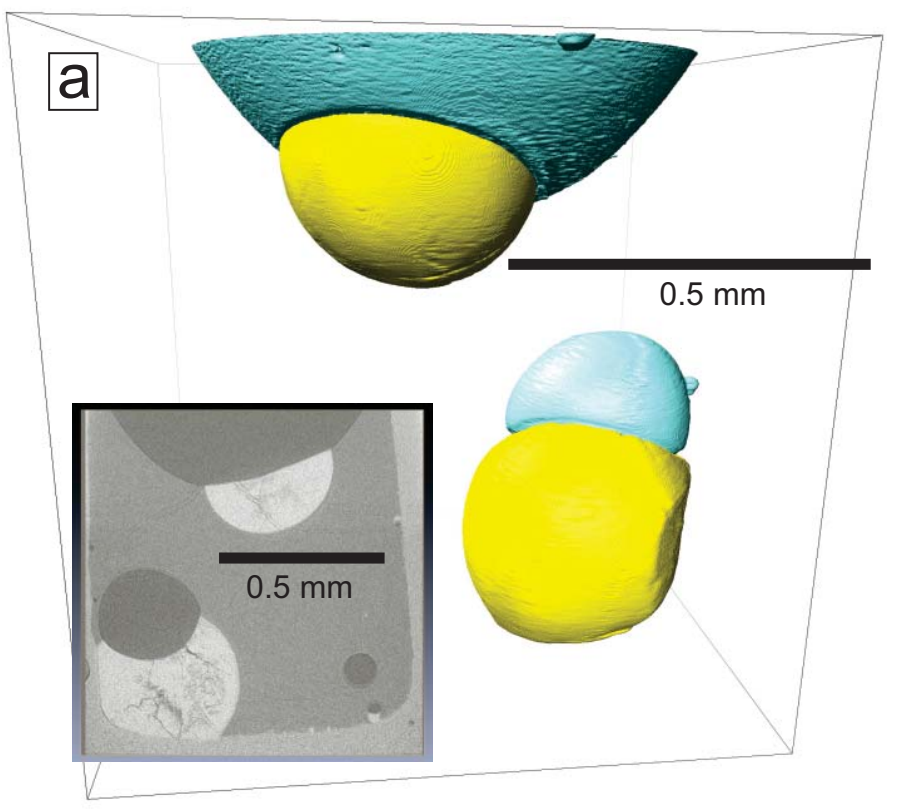




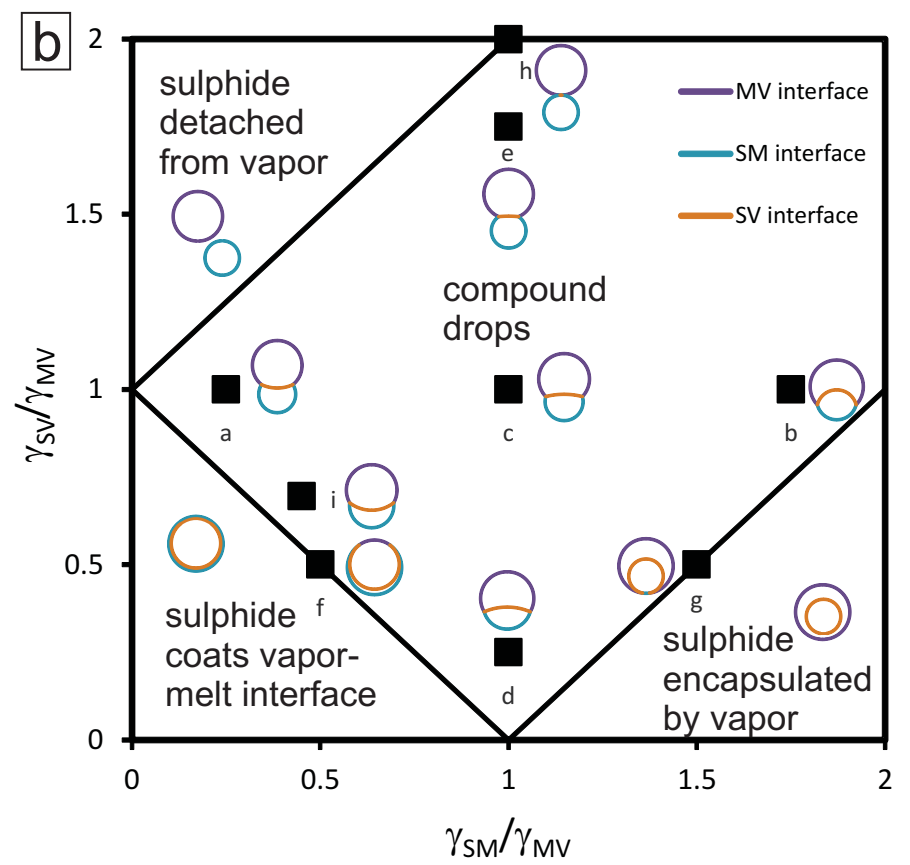




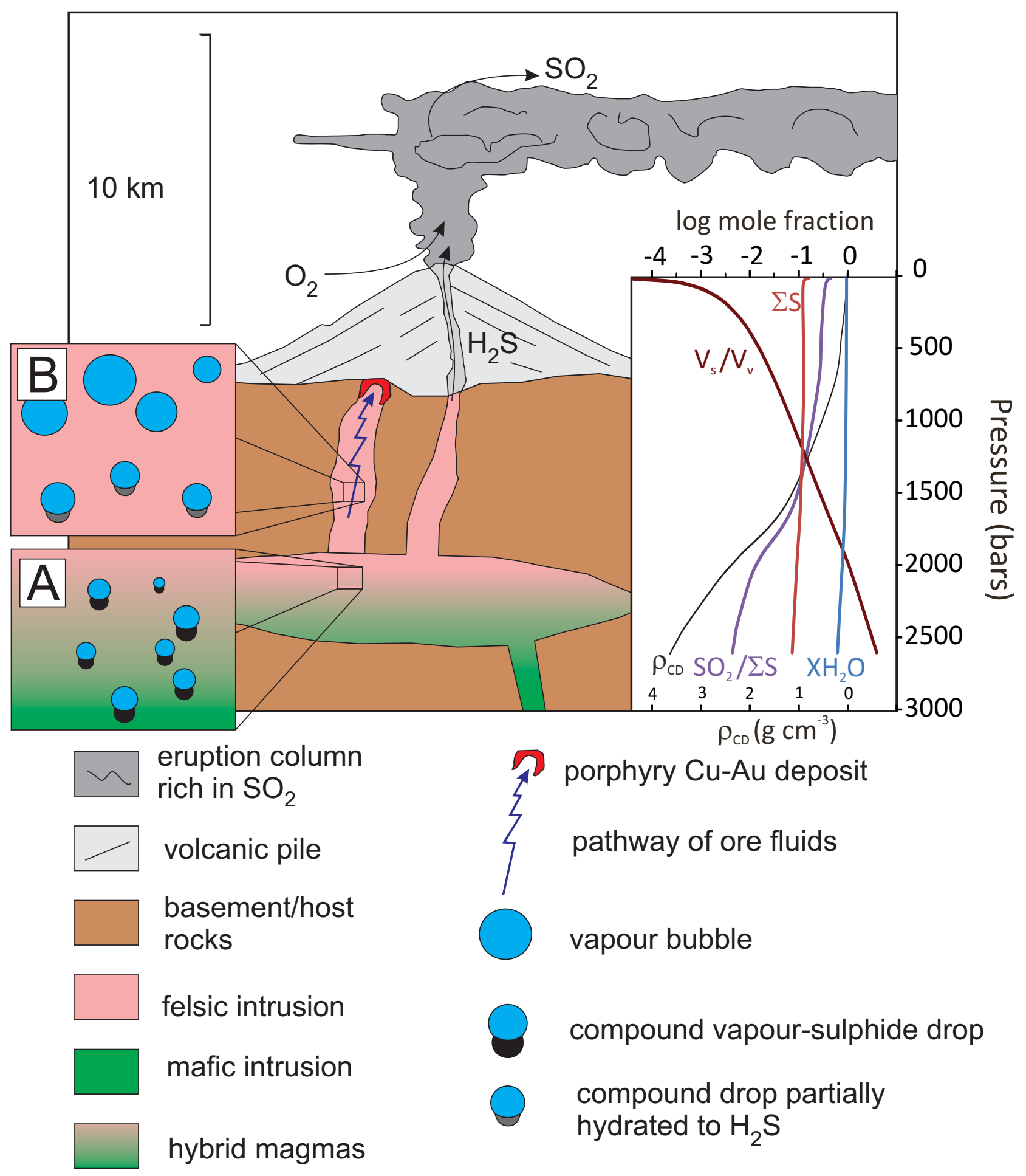




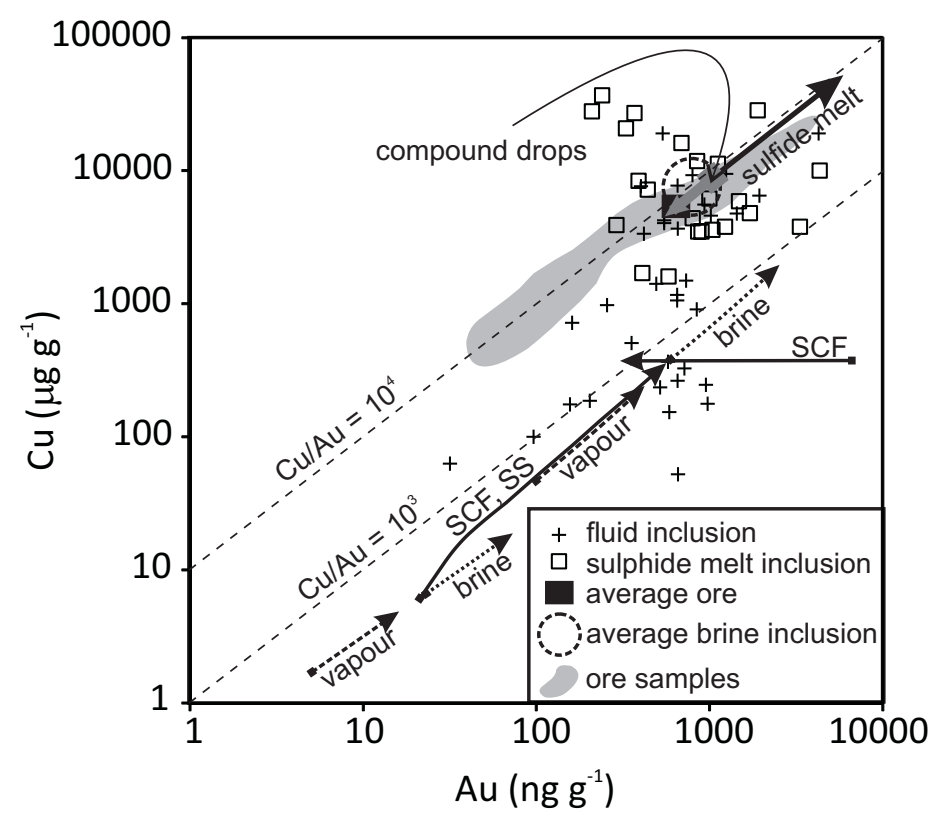

